\title{
Modeling and Simulation of Atmospheric Water Generation Unit Using Anhydrous Salts
}

\author{
Shereen K. Sibie ${ }^{1}$ Mohamed F. El-Amin ${ }^{2}$ and Shuyu Sun ${ }^{3}$ \\ ${ }^{1}$ MSc Student in Renewable Energy Eng., College of Engineering, Effat University, Jeddah, \\ 21478, KSA; shsibie@effatuniversity.edu \\ ${ }^{2}$ Energy Research Lab., College of Engineering, Effat University, Jeddah, 21478, KSA; \\ momousa@effatuniversity.edu \\ ${ }^{3}$ Division of Physical Sciences and Engineering (PSE), King Abdullah University of Science \\ and Technology (KAUST), Thuwal, 23955-6900 Jeddah, KSA
}

\begin{abstract}
The atmosphere contains 3400 trillion gallons of water vapor, which would be enough to cover the entire earth in 1 inch of water. Air humidity is available everywhere, and it acts as a great alternative as a renewable reservoir of water known as atmospheric water. Atmospheric water harvesting system efficiency depends on the sorption capacity of water based on the adsorption phenomenon. Using anhydrous salts is an efficient process for capturing and delivering water from ambient air, especially at a low relative humidity as low as $15 \%$. A lot of water-scarce countries like Saudi Arabia have much annual solar radiation and relatively high humidity. This study is focusing on modeling and simulating the water absorption and release of the anhydrous salt copper chloride $\left(\mathrm{CuCl}_{2}\right)$ under different relative humidity to produce atmospheric drinking water in scarce regions.
\end{abstract}

Keywords: Atmospheric water; anhydrous salts; absorption; relative humidity; modeling; simulation.

\section{Introduction}

About four billion people, two-thirds of the world population, suffer from water scarcity [1]. And about 13 sextillions $\left(10^{21}\right)$ liters of water vapor exist in the atmosphere [2]. The atmospheric water, which is considered a substantial renewable reservoir of water and enough to meet every person's needs on the planet, is unfortunately ignored [3]. Atmospheric water usually exists in three types: fog, water vapor in the air, and clouds. Cloud and fog are all made up of tiny drops of water, typically with a diameter from 1 to $40 \mathrm{~mm}$, compared with the size of rain droplets varying from 0.5 to $5 \mathrm{~mm}$. Still, the concentration of water droplets in fog is usually larger. Water vapor is a recyclable natural resource with the potential to water the world's arid regions [4]. Real challenges are facing Saudi Arabia due to the depletion of the rapidly used nonrenewable groundwater. In Saudi Arabia, the water is extremely scarce due to the arid climate conditions. The high water demand in the agriculture sector is exacerbating the water scarcity situation in the Kingdom. Urban water and sanitation services incur a high cost 
to the government [5]. Besides, there is always plenty of water available in the atmosphere, even in very dry desert regions [6].

Methods to harvest water from humid air are known [3-10], . and currently, 25 countries worldwide are capturing atmospheric water droplets from the fog for the remote villages[8-12]. However, the fog harvesting technique requires a frequent presence of high relative humidity $(\mathrm{RH})$, typically $100 \%$ in the air, making it viable in limited locations. Witch restrains this technology to be applied in any other site unless it has a very high RH $[13,14]$. Further, There have been efforts to meet limited success to harvest water vapor from a low RH air to produce water with a self-sustained energy source $[3,15]$. In 2017, Yaghi and Wang et al. demonstrated water harvesting by vapor adsorption using a porous metal-organic framework that works in low RH of $20 \%$ and delivers water using low-grade heat natural sunlight assisted by photothermal material [16]. More recently, $\mathrm{Li}$ and Shi et al. have fabricated an all-in-one bilayered composite disk device to integrate water vapor collection, and photothermal assisted water release using anhydrous salts Copper chloride $\left(\mathrm{CuCl}_{2}\right)$, Copper sulfate $\left(\mathrm{CuSO}_{4}\right)$, and Magnesium sulfate $\left(\mathrm{MgSO}_{4}\right)$ with low relative humidity as low as $15 \%$ [17].

This paper will model and simulate atmospheric water generation unit using anhydrous salts; Copper chloride $\left(\mathrm{CuCl}_{2}\right)$ salt to produce atmospheric water from thin air.This study explores and investigates the potential of harvesting atmospheric water using a cost-effective material like anhydrous salt. Also, identify the potential of modeling and simulation of the absorption and release of water from ambient air using anhydrous salt to produce atmospheric water .

\section{$2 \quad$ Mathematical Modeling}

In this work, we consider the model developed by Cesek et al. [18], which was originally used to describe the vapor absorption in porous cellulosic fiber web. Fick's first law can describe the one-dimensional diffusion of molecules in the perpendicular direction of the porous material into thin layer (Fig. 1) as:

$$
-D \frac{d C}{d t}=C_{0} \varphi\left(\frac{d x}{d t}\right)^{2}
$$

where $C$ is the actual vapor concentration and $C_{0}$ is the saturated vapor concentration. $\mathrm{D}$ is the diffusion coefficient, and $\varphi$ is the relative humidity, and $x$ is the thickness of the absorbent material. Now, let us assume that:

$$
Y=Y_{e} \frac{x}{x_{r a}}
$$

Here $Y_{e}$ is the moisture content of the condensed component at time $t \rightarrow \infty$, while $Y$ is the moisture content of the condensed component at any time $t$ and $x_{r a}$ is half of the thickness. 


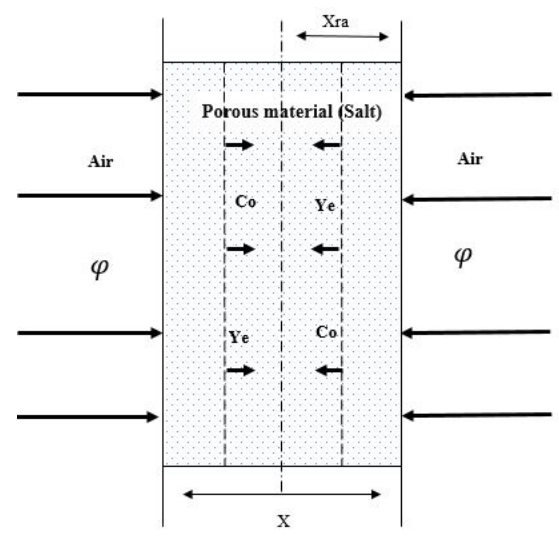

Figure 1. Schematic diagram of the system under consideration.

The variation of diffusion and absorption in the porous material is proportional to the relative concentration variation of the condenser water inside the absorbent, which is described as:

$$
D \frac{d Y}{d t}=\frac{C_{0} \varphi M \varepsilon}{\rho_{p}}\left(\frac{d x}{d t}\right)^{2}
$$

Where $\mathrm{M}$ is the molecular weight of the water, $\rho_{p}$ Is the apparent density, and $\varepsilon$ is the porosity of the salt. Assuming that the concentration gradient on the boundary of the porous material is constant, the velocity of the penetration on the boundary becomes:

$$
\frac{d x}{d t}=k^{0.5}\left(\frac{x}{t^{\frac{d+1}{2}}}\right)
$$

Where $\mathrm{k}$ is the proportionality coefficient that will be taken $(k=1)$ in our calculations. The parameter $d$ characterizes a uniformity of the stratified structure of porous material. When $d=1$, the porous material is uniformly stratified. However, if $d>1$ or $d<1$, the porous material is non-uniformly stratified [18]. From the above equations, a simplified differential equation can be obtained as:

$$
D \frac{d Y}{d t}=\frac{k C_{0 \varphi} M \varepsilon Y^{2}}{\rho p}\left(\frac{x_{r a}}{Y_{e}}\right)^{2} \frac{1}{t^{d+1}}
$$

Which is a separable equation that can be solved easily to give [18]:

$$
Y=\frac{Y_{e} t^{d}}{\left(\frac{\varphi x_{r a}^{2}}{D p_{s} d Y_{e}}\right)+t^{d}}
$$

such that $D_{p s}=D \rho_{p} / k C_{0} M \varepsilon$. 


\section{Model Validation}

Eq. (6) is used to validate our computed model, and this section presents a comparison between the current computed water content against the experimental data obtained from the literature [17].

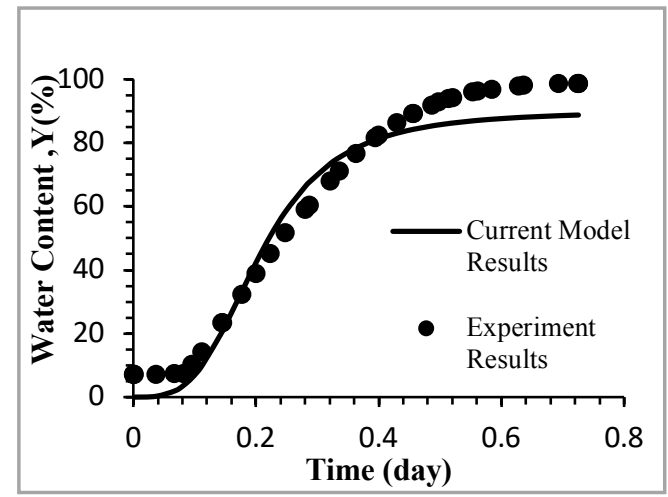

Figure 2. Comparison between the current computed water content against the experimental data [17].

In Fig. 2, the current computed model presents the current moisture content in the Copper chloride $\left(\mathrm{CuCl}_{2}\right)$, under $\mathrm{RH} 15 \%$, it reaches the maximum saturation rate of 88.748 (Kg L/ Kg S) after 17.4 hours of hydration. Compared with the experimental results [17] with an $8.3 \%$ maximum absolute error. Table 1 presents the parameter used for the current model simulation.

Table 1. The initial data for the current model are listed in Table 1

\begin{tabular}{ccc}
\hline Parameters & Value & Unit \\
\hline Ye & 0.9 & $(\mathrm{Kg} \mathrm{L} / \mathrm{Kg} \mathrm{S})$ \\
$\mathrm{t}$ & 1 & (Day) \\
$\mathrm{d}$ & 3.4 & (Dimensionless) \\
$\varphi$ & 15 & Relative Humidity in \% \\
$x_{r a}$ & 0.0015 & $(\mathrm{~m})$ \\
$D_{p s}$ & 0.002720402 & $\mathrm{~m}^{2} \mathrm{~kg} \mathrm{~S} / \mathrm{kg} \mathrm{Ldayd}$ \\
\hline
\end{tabular}

\section{$4 \quad$ Results}

\subsection{Sensitivity of the porosity $(\varepsilon)$}

The $\varepsilon$ resembles the total porosity of the pore sample, as it can be calculated on knowing the apparent density of the porous material $\rho_{P}[18]$.

$$
\varepsilon=1-\frac{\rho_{P}}{\rho_{\mathrm{s}}}
$$


where $\rho_{s}$ is the density of the solid part of the porous material. The Copper chloride $\left(\mathrm{CuCl}_{2}\right)$ has a density of $3386 \frac{\mathrm{Kg}}{\mathrm{m} 3}$.

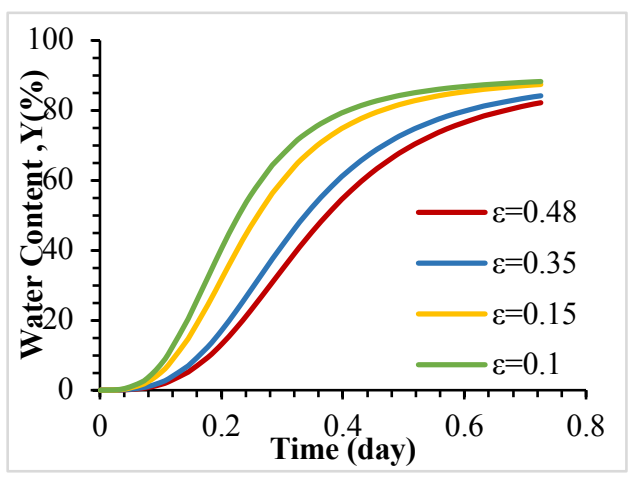

Figure 3. Water content curves of $\mathrm{CuCl}_{2}$ under different porosity $\varepsilon$.

All parameters for the current model were constant (Table1) except $\varepsilon$ was tested with different values shown in (Fig. 3). As it shows, the more uniform the salt, the more water content the salt holds. The smaller the pore volume ( smaller porosity), the faster the salt diffusion rate due to the decrease in the diffusion path, which increases the water content in the salt.

\subsection{Sensitivity of the thickness $\left(x_{r a}\right)$}

The $x_{r a}$ resembles half-thickness of the sample, as this parameter has an essential effect on the absorption rate behavior on the Copper chloride $\left(\mathrm{CuCl}_{2}\right)$. The initial values are $1.5 \mathrm{~mm}$, as other values were used in the (Fig. 4) to observe the water content's behavior in the salt.

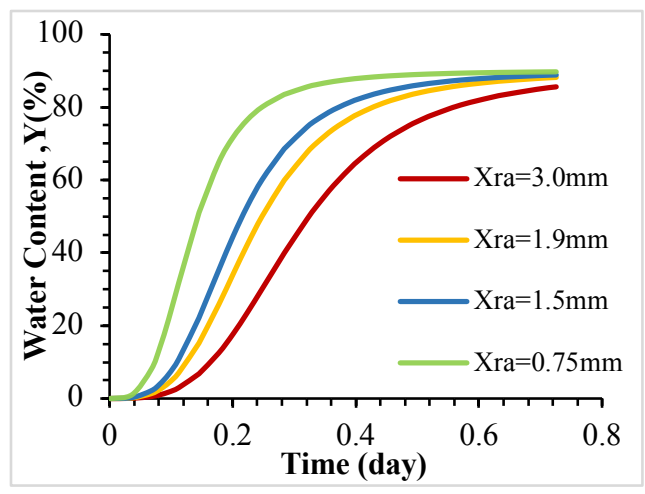

Figure 4. Water vapor absorption curves of $\mathrm{CuCl}_{2}$ under the different thickness.

The thickness of the salt plays an important role in the time and water content in the salt. As the thickness decreases, it allows the salt to absorb the water vapor faster as the water content increases. 


\subsection{Sensitivity of the uniformity of the stratified structure (d)}

The $\mathrm{d}$ resembles the uniformity of stratified structure of porous web material, for the Copper chloride $\left(\mathrm{CuCl}_{2}\right)$ the initial value was $\mathrm{d}=3.2$ (dimensionless). The results in (Fig. 5) showed more weight of the water is gained with less time in the salt when the salt is more uniform. The salt takes more time and gains less weight of the water content when it is less uniform. As the uniformity of the stratified structure of the $\mathrm{CuCl} 2$ plays a role in the kinetics of the process.

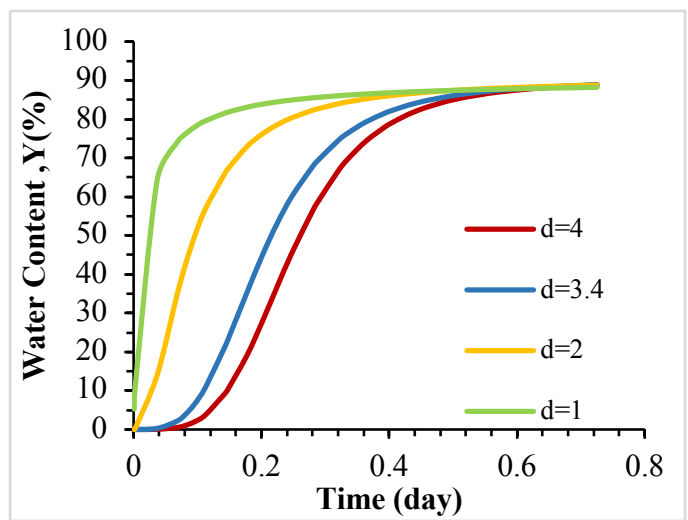

Figure 5. Water vapor absorption curves of $\mathrm{CuCl}_{2}$ under different uniformity of the stratified structure $(d)$.

\section{Conclusion}

In conclusion, atmospheric water is considered a huge renewable reservoir, as recently researchers have been developing different techniques and materials to absorb water from the atmosphere. Extracting water vapor from thin air using anhydrous salt is one of the efficient and cost-effective materials up-to-date. It is economical and practical. This paper was devoted to model and simulate water vapor absorption from the air using anhydrous salt copper chloride $\left(\mathrm{CuCl}_{2}\right)$. An analytical model was developed. The results are compared to experimental ones with a good agreement with maxiumum absolute error of $88.3 \%$; different sensitivity analyses were obtained, including different porosity, the thickness of the sample, and uniformity of the stratified structure. Those key parameters were selected to examine the effect of the efficiency of the absorbent materials. It was found that the moisture content in the Copper Chloride $\left(\mathrm{CuCl}_{2}\right)$, under $\mathrm{RH}$ of $15 \%$, it reaches the maximum saturation rate of $88.748(\mathrm{Kg} \mathrm{L} /$ $\mathrm{Kg} \mathrm{S}$ ) after 17.4 hours of hydration.

\section{References}

[1] M. Mekonnen and A. Hoekstra, "Four billion people facing severe water scarcity," Sci. Adv., vol. 2, e1500323, 2016. 
[2] P. H. Gleick, "Water and Conflict: Fresh Water Resources and International Security," Int. Secur., vol. 18, no. 1, pp. 79-112, 1993.

[3] R. V. Wahlgren, "Atmospheric water vapour processor designs for potable water production: a review," Water Res., vol. 35, no. 1, pp. 1-22, Jan. 2001.

[4] "Practical water production from desert air | Science Advances Homepage." https://advances.sciencemag.org/content/4/6/eaat3198.

[5] "National-Water-Strategy-Homepage". https://www.mewa.gov.sa/en/Ministry/Agencies/ TheWaterAgency/Topics/Pages/Strategy.aspx.

[6] S. Schneider, T. Root, and M. Mastrandrea, Encyclopedia of Climate and Weather, Second Edition - Stephen H. Schneider; Michael Mastrandrea; Terry L. Root - Oxford University Press. Oxford University Press, 2011.

[8] K.-C. Park, S. Chhatre, S. Srinivasan, R. Cohen, and G. Mckinley, "Optimal Design of Permeable Fiber Network Structures for Fog Harvesting," Langmuir ACS J. Surf. Colloids, vol. 29, Jul. 2013.

[9] L. Zhang, J. wu, M. Hedhili, X. Yang, and P. Wang, "Inkjet printing for direct micropatterning of a superhydrophobic surface: Toward biomimetic fog harvesting surfaces," J Mater Chem A, vol. 3, pp. 2844-2852, 2014.

[10] Yuchao Wang, Lianbin Zhang, Jinbo Wu, Mohamed N. Hedhili, and Peng Wang, "A facile strategy for the fabrication of a bioinspired hydrophilic-superhydrophobic patterned surface for highly efficient fog-harvesting," J Mater Chem A, vol. 3, pp. 18963-18969, 2015.

[11] J. Ju, H. Bai, Y. Zheng, T. Zhao, R. Fang, and L. Jiang, "A multi-structural and multifunctional integrated fog collection system in cactus," Nat. Commun., vol. 3, pp. 1247, 2012.

[12] Y. Zheng et al., "Directional water collection on wetted spider silk," Nature, vol. 463, pp. 640-643, 2010.

[13] Guntae Kim, Su-Ji Gim, Seung-Min Cho, N. Koratkar, and Il-Kwon Oh, "Graphene Films: Wetting-Transparent Graphene Films for Hydrophobic Water-Harvesting Surfaces," Advanced Materials, vol. 26, pp. 5070-5070, 2014.

[14] J. Olivier and C. J. Rautenbach, "The implementation of fog water collection systems in South Africa," Atmospheric Res., vol. 64, pp. 227-238, Sep. $2002 .$.

[15] M. Estrela, J. Valiente, D. Corell, and M. Millán, "Fog collection in the Western Mediterranean Basin (Valencia region, Spain)," Atmospheric Res. - ATMOS RES, vol. 87, pp. 324-337, 2008.

[16] J. G. Ji, R. Z. Wang, and L. X. Li, "New composite adsorbent for solar-driven freshwater production from the atmosphere," Desalination, vol. 212, no. 1, pp. 176-182, Jun. 2007.

[17] Hyunho Kim et al., "Water harvesting from air with metal-organic frameworks powered by natural sunlight," Science 356, 6336, pp. 430-434, 2017.

[18] Renyuan Li, Yusuf Shi, Le Shi, Mossab Alsaedi, and Peng Wang, "Harvesting Water from Air: Using Anhydrous Salt with Sunlight," Environmental Science \& Technology, vol. 52, pp. 5398-5406, 2018.

[19] B. Cešek, M. Milichovský, and F. Potucek, "Kinetics of Vapour Diffusion and Condensation in Natural Porous Cellulosic Fibre Web,” Int. Sch. Res. Notic., vol. 2011, Article ID 794306, 2011. 